Class Conflict and Economic Development in Chile, 1958-1973 



\section{Class Conflict and Economic Development in Chile, 1958-1973}

BARBARA STALLINGS

STANFORD UNIVERSITY PRESS

Stanford, California

सै। 


\section{Stanford University Press}

Stanford, California

(C) 1978 by the Board of Trustees of the

Leland Stanford Junior University

IS B N 0-8047-0978-5

LC 77-89I 8 I

Published with the assistance of the Andrew W. Mellon Foundation 
To my parents in hopes that this book will help them better understand what the Unidad Popular experience was all about and to the memory of Charles Horman and Frank Teruggi who understood very well 
